\title{
The Cell Death Phenotype of MGC-803 Cells Inducing with "Dextran- Magnetic Layered Double Hydroxide-Fluorouracil" Drug Delivery System and Fluorouracil
}

\author{
Qinyu Pei, ${ }^{a, b, \#}$ Rui Wang, ${ }^{b, \#}$ Chunhua Shu, ${ }^{a}$ Xiuying Pei, ${ }^{b}$ Xue Li,${ }^{b}$ and GuoJing Gou*,a,c \\ ${ }^{a}$ Department of Pharmaceutics, College of Pharmacy, Ningxia Medical University; Yinchuan 750004, China: \\ ${ }^{b}$ Department of Pharmacology, Key Laboratory of Ministry of Education in Fertility Preservation and Maintenance, \\ Ningxia Medical University; Yinchuan 750004, China: and ${ }^{c}$ Medical Chemistry Department, School of Basic Medical, \\ Ningxia Medical University; Yinchuan 750004, China. \\ Received November 29, 2018; accepted May 7, 2019; advance publication released online May 18, 2019
}

The purpose of the paper is to study the differences in cell death mechanism of MGC-803 induced by "dextran-magnetic layered double hydroxide-fluorouracil" (DMF) drug delivery system and 5-Fluorouracil (5-Fu), respectively. The inhibitory effect on the proliferation was detected via CCK-8. The morphology of cell death was detected by transmission electron microscopy (TEM). Intracellular ATP, mitochondrial membrane potential (MMP), reactive oxygen species (ROS) and Cytosolic Free Ca $\left(\mathrm{Ca}^{2+}\right)$ level were detected via some methods. The result showed that DMF had more obvious effect in suppressing proliferation compared with 5-Fu, and changed cell death pattern of 5-Fu from apoptosis to oncosis. The ATP decrease, MMP loss, $\mathrm{Ca}^{2+}$ increase, the activation of uncoupling protein-2 (UCP-2) and calpain-1 were significant after DMF exposure. However, DMF did not result in ROS accumulation. DMF could involve in activation of porimin, and the cascade reaction of caspases-3, -7, -9, and -12 and poly ADP-ribose polymerase (PARP) through Western blot. DMF showed a stronger injury on nuclear membrane in the cascade reaction of caspases-6, -8 and lamin-A. DMF triggered rapid depletion of ATP, which was consistent with the phenotype of oncosis. Endogenous mitochondrial apoptosis might not be the main cause of cell swelling. DMF could induce strong endoplasmic reticulum stress (ERS) effect, there might be some signaling pathways related with ERS during the process of oncosis. The calpain system might not be a key factor for structural damage in oncosis induced by DMF. DMF could induce the caspases cascade reactions similar to apoptosis, but inflicted a more strong damage on nuclear membrane and PARP.

Key words dextran-magnetic layered double hydroxide-fluorouracil; oncosis; death mechanism; MGC-803

\section{INTRODUCTION}

Gastric cancer is a commonly malignant tumor in digestive system and a major public health burden as one of the most frequently cancer especially in Eastern Asia. So far, curative therapy still plays an important role in gastric cancer. However, there is only small part of the total drug to reach the target area after intravenous or oral administration. ${ }^{1)}$ A large amount of non-target area drug has serious side effects for patients. 5-Fluorouracil (5-Fu), a well-known anti-cancer drug, has the cytotoxic effect in human gastric cancer MGC-803 cell by induction apoptosis, also exist severe side effects in large dose. ${ }^{2}$ Additionally, it is not only complicated for synthesis process but also difficult for design slow-release drugs if use ordinary magnetic substance $\mathrm{Fe}_{3} \mathrm{O}_{4}$ to carry drug such as 5-Fu. There may be the degradation problem of the $\mathrm{Fe}_{3} \mathrm{O}_{4}$ carrier.

To overcome above disadvantages, we established a new dual-function carrier, a magnetic layered double hydroxide (MLDH) with it to integrate magnetic targeting and slowly release functions. Based on MLDH, a supramolecular drug delivery system of "dextran-magnetic layered double hydroxidefluorouracil" (DMF) was developed. ${ }^{3-6)}$ DMF has excellent cell transport properties and obvious anti-tumor effects. It can be seen from the living cell imaging in vitro that the cells

\footnotetext{
\# These authors contributed equally to this work.

undergo expansion and rupture in MGC-803 stimulated by DMF, and the cell contents lost eventually, ${ }^{5)}$ those are consistent with the characteristics of oncosis. Therefore, we initially concluded that DMF would induce oncosis in MGC-803 cell, and 5-Fu induce apoptosis of the same cell.

In 1997, the American Society of Toxicology and Pathology recommended to the Cell Death Nomenclature Committee to classify cell death forms into apoptosis, oncosis, and unregulated autophagy according to the pathological diagnostic criteria for cell death. Oncosis refers to the pre-lethal phase that follows a lethal cell injury such as complete ischemia or the effects of many chemical toxins, ${ }^{7,8)}$ which is a new form of cell death different from apoptosis. They can be distinguished mainly on cell volume and nuclear morphology. Apoptosis characterized by the cells shrinking and forming of apoptotic body. ${ }^{9)}$ Oncosis related to typical features including cell swelling, dilatation of the endoplasmic reticulum (ER), mitochondrial condensation, formation of cytoplasmic blebs or blisters free of organelle. ${ }^{10)}$ As so far, the majority of literatures use apoptosis ways to study oncosis, including some signal cascades that similar to the mechanism of apoptosis (but there are still some differences). ${ }^{11,12)}$ Therefore, we used some similar ways of apoptosis to research the difference between $5-\mathrm{Fu}$ and DMF in mechanisms. The study suggested that the mechanism of apoptosis induced by 5-Fu were mainly involved in caspase family of extracellular and intracellular pathway, such 
as caspases-3, -8 , and $-9 .{ }^{13)}$ We assumed that the mechanism of DMF treatment are similar or different to these of oncosis in previous researches. In addition, DMF and 5-Fu are likely to show some similar mechanisms of apoptosis in MGC-803. In order to explore the oncosis peculiarity stimulated by DMF, this paper intends to study mitochondrial and endoplasmic reticulum pathway through cellular immune-fluorescence, molecular Western blot and other detection of related factors in oncosis. We expected to provide research basis for the development of DMF anticancer agents in the treatment of gastric cancer through exploration of mechanisms induced by $\mathrm{DMF}$ in MGC-803.

\section{MATERIALS AND METHODS}

Cell Culture and Reagent Human gastric cancer cell line MGC-803 was incubated in culture medium containing RPMI 1640 with 10\% Fetal bovine serum (FBS) and 1\% penicillin and streptomycin in a humidified environment of $37^{\circ} \mathrm{C}$ and $5 \% \mathrm{CO}_{2}$. Cell Counting Kit-8 (CCK-8) obtained from Dojindo Laboratories in Japan. Fluo-3AM purchased from Sigma Chemical Co., Ltd. (Silicon Valley, CA, U.S.A.). Antibodies against caspases-3, -6, -8, and so on were obtained from Abcam Co., Ltd. (Cambridge, MA, U.S.A.). Porimin purchased from Bioss Antibodies Co., Ltd. (Beijing, China). Fluorescein-conjugated Goat anti-Rabbit immunoglobulin $\mathrm{G}(\mathrm{IgG})$ $(\mathrm{H}+\mathrm{L})$ was from ZSGB-BIO Co., Ltd. (Beijing, China). Other routine laboratory reagents obtained from commercial sources.

Cell Viability Assay Cells were seeded on 96-well plates with the density of $4 \times 10^{3}$ cells per well. After overnight, the cells were treated with alteration in concentration $(125$, $250,500,1000$, and $2000 \mu \mathrm{g} / \mathrm{mL}$ ) of $5-\mathrm{Fu}$ and $\mathrm{DMF}$ at $37^{\circ} \mathrm{C}$ for $24 \mathrm{~h}$, respectively. In addition, cells having grown for $24 \mathrm{~h}$ were exposed to $350 \mu \mathrm{g} / \mathrm{mL}$ of $5-\mathrm{Fu}$ and $1 \mathrm{mg} / \mathrm{mL}$ of $\mathrm{DMF}$ (contain approximately $35 \% 5-\mathrm{Fu}$ ) for 12,24 , and $48 \mathrm{~h}$. Thereafter, $10 \mu \mathrm{L}$ CCK- 8 added to each well and incubated for $2 \mathrm{~h}$. Absorbance value recorded at a wavelength of $450 \mathrm{~nm}$ by the microplate reader (MULTISKAN GO, Thermo Fisher, U.S.A.).

Transmission Electron Microscopy (TEM) Cells were seeded on 6-well plates with the density of $1 \times 10^{7}$ cells per well. After $12 \mathrm{~h}$ incubation, $350 \mu \mathrm{g} / \mathrm{mL} 5-\mathrm{Fu}$ and $1 \mathrm{mg} / \mathrm{mL}$ DMF (contain approximately $35 \% 5$-Fu) were added to 6 -well plate at $37^{\circ} \mathrm{C}$ with $5 \% \mathrm{CO}_{2}$ for $4 \mathrm{~h}$, respectively. The experimental and control cells were fixed with $2 \%$ glutaraldehyde, post fixed in $1 \%$ osmium acid, dehydrated through the ethanol of different concentration and embedded in epoxy resin. Semithin-sections cut axially, through all layers of each pellet to select areas for ultramicrotomy. Ultrathin sections stained with lead citrate and 4\% uranyl acetate and then observed in a HITACHI H7650 electron microscope (Hitachi, Japan).

Intracellular ATP Assay Cells were harvested during logarithm growth phase and plated in 6-well plates at a density of $3 \times 10^{5}$ cells per well in a volume $2 \mathrm{~mL} /$ well while set of untreated control group. After $12 \mathrm{~h}$ incubation, $350 \mu \mathrm{g} / \mathrm{mL}$ $5-\mathrm{Fu}$ and $1 \mathrm{mg} / \mathrm{mL} \mathrm{DMF}$ (contain approximately 35\% 5-Fu) were added to 6 -well plate at $37^{\circ} \mathrm{C}$ with $5 \% \mathrm{CO}_{2}$ for 12,24 , and $48 \mathrm{~h}$, respectively. Cells collected by trypsinization and centrifugation. Total protein was isolated from cells using Whole Cell Lysis kit following the manufacturer's instruction at $4{ }^{\circ} \mathrm{C}$ to collect supernatants, and protein concentration was determined using the bicinchoninic acid (BCA) protein quantitation kit. The concentration of ATP performed with a commercial ATP detection kit according to the manufacturer's instructions. Finally, the absorbance values of each tube measured by microplate reader, taken into the formula provided by the manufacturer's instructions. The experiment tested at least three times in parallel.

Mitochondrial Membrane Potential (MMP) Assay MMP was measured by flow cytometry with the mitochondrial tracking fluorescent JC-1. After exposed to $350 \mu \mathrm{g} / \mathrm{mL}$ $5-\mathrm{Fu}$ and $1 \mathrm{mg} / \mathrm{mL}$ (contain approximately 35\% 5-Fu) DMF for 12,24 , and $48 \mathrm{~h}$, cells were harvested and centrifuged at $1000 \mathrm{rpm}$ for $5 \mathrm{~min}$. Thereafter, cells incubated with JC-1 at $37^{\circ} \mathrm{C}$ for $20 \mathrm{~min}$ in the dark. Subsequently the cells resuspended in $500 \mu \mathrm{L} 1 \times$ incubation analyzed by flow cytometer (BD Accuri C6). The data was analyzed using BD Accuri $\mathrm{C}_{6}$ software and expressed as mean fluorescence intensity.

Reactive Oxygen Species (ROS) Assay 2',7'-Dichlorodihydrofluorescin diacetate (DCFH-DA) is a fluorogenic freely permeable tracer specific for ROS assessment. It can be deacetylated by intracellular esterase to the non-fluorescent DCFH, which is oxidized by ROS to the fluorescent compound 2',7'-dichloroflorescein (DCF). Thus, the fluorescence intensity of DCF is proportional to ROS generated in the cells. Cells harvested during logarithm growth phase and seeded in 6 -well plates at a density of $3 \times 10^{5}$ cells $/ \mathrm{mL}$ in a final volume $2 \mathrm{~mL} /$ well. After $12 \mathrm{~h}$ incubation, $350 \mu \mathrm{g} / \mathrm{mL} 5-\mathrm{Fu}$ and $1 \mathrm{mg} / \mathrm{mL}$ DMF (contain approximately 35\% 5-Fu) were added to 6 -well plates at $37^{\circ} \mathrm{C}$ with $5 \% \mathrm{CO}_{2}$ for 12,24 , and $48 \mathrm{~h}$, respectively. Cells washed once with ice-cold phosphate buffered saline (PBS) incubated with $4 \mu \mathrm{mol} / \mathrm{L} \mathrm{DCFH}-D A$ at $37^{\circ} \mathrm{C}$ for $10 \mathrm{~min}$ in the dark. Then the cells were washed five times in PBS followed by collecting in $1 \mathrm{~mL}$ PBS. The ROS production assessed by flow cytometer. The experiment performed at least three times.

Cytosolic Free Ca Concentration $\left(\mathrm{Ca}^{2+}\right)$ Assay Upon entering the cell, Fluo-3 AM is cleaved by esterase to form Fluo-3, followed by retained and hardly any fluorescence in the cell. However, there is an intense increase for fluorescence intensity when Fluo-3 combines with calcium ions. Thus, the fluorescence intensity of Fluo-Ca is proportional to the great mass of $\mathrm{Ca}^{2+}$ generated by the cells. After drugs exposure, cells were washed in ice-cold Hank's balanced salt solution (HBSS) for three time. A working Fluo-3AM solution was added in cells with concentration of $4 \mu \mathrm{M}$ and incubated at $37^{\circ} \mathrm{C}$ for $45 \mathrm{~min}$ in the dark. Then cells was covered with HBSS that contain $1 \% \mathrm{FBS}$ at $37^{\circ} \mathrm{C}$ for $60 \mathrm{~min}$ in the dark to ensure that Fluo-AM is compete de-esterification. Cells were resuspended in HBSS. The $\mathrm{Ca}^{2+}$ generation was assessed by flow cytometer. The data of DCF fluorescence intensity was evaluated by $\mathrm{BD}$ Accuri $\mathrm{C}_{6}$ software.

Immunocytochemistry Assay Cells harvested during index growth phase and seeded in 12-well plates at a density of $5 \times 10^{4}$ cells $/ \mathrm{mL}$ in a final volume $1 \mathrm{~mL} /$ well. After $24 \mathrm{~h}$ incubation, $350 \mu \mathrm{g} / \mathrm{mL} 5-\mathrm{Fu}$ and $1 \mathrm{mg} / \mathrm{mL}$ DMF was added to 12 -well plates at $37^{\circ} \mathrm{C}$ with $5 \% \mathrm{CO}_{2}$, respectively. The cell monolayer fixed with methanol on ice for $30 \mathrm{~min}$ and washed three times with PBS. Subsequently, cells blocked with $1 \%$ BSA for $1 \mathrm{~h}$ at the room temperature under gentle shaking. After washing in PBS, the cells were incubated with primary antibody against porimin through overnight incubation at $4^{\circ} \mathrm{C}$. Cells washed three times by PBS and incubated with 
appropriate secondary antibody conjugated to horseradish peroxidase for one hour at room temperature in dark condition. The microscope cover glass was placed on a dry slide with 4',6-diamidino-2-phenylindole (DAPI) to counterstain and seal. After completion, the position and fluorescence intensity of the primary antibody and cell morphology observed under a DP20-5 inverted microscope (OLYMPUS, Japan).

Western Blot Analysis The cell was treated with 5-Fu and DMF for indicate time in indicate concentration. Total protein was isolated from cells using Whole Cell Lysis kit containing phosphatase inhibitor $500 \mu \mathrm{g} / \mathrm{mL}$, protease $5 \mu \mathrm{g} / \mathrm{mL}$, PMSF $500 \mu \mathrm{g} / \mathrm{mL}$ following the manufacturer's instruction at $4^{\circ} \mathrm{C}$ to collect supernatants for Western blot. Protein concentration was determined using the BCA Protein Quantitation Assay by Spectrophotometer. Sample of protein $(10 \mu \mathrm{g})$ loaded on 8 or $10 \%$ sodium dodecyl sulphate polyacrylamide gels and transferred to immobilon-P polyvinylidene difluoride membrane (PVDF) with $100 \mathrm{~V}$. It was blocked using 5\% skimmed milk in Tris buffer saline (TBS) with $0.1 \%$ Tween 20 (TBS-T) for $1 \mathrm{~h}$ at room temperature. After washing in PBS, the cells incubated with primary antibody against such as caspase-3 (1:1000). After overnight incubation at $4^{\circ} \mathrm{C}$, cells were washed three times in TBS-T and incubated with appropriate secondary antibody conjugated to horseradish peroxidase for one hours at room temperature and then washed in TBS-T. The membranes performed with enhanced chemiluminescence (ECL) Western blot detection system (BIO-RAD, U.S.A.). The densitometry developed using Image $\mathrm{J}$ analysis software. The protein levels normalized to protein glyceraldehyde-3-phosphate dehydrogenase (GAPDH) and expressed relative to control.

Statistical Analysis All the data were expressed as mean \pm standard deviation (S.D.) from three individual experiments. Differences between groups were determined by using Student's $t$-test and one-way ANOVA. $p<0.05$ was deemed statistically significant.

\section{RESULTS AND DISCUSSION}

DMF Exert Potent Effect in Suppressing Proliferation against MGC-803 The early study showed that the cell viability was related to 5-Fu, along with MLDH carrier that may also play a role in specific organelles after DMF exposure

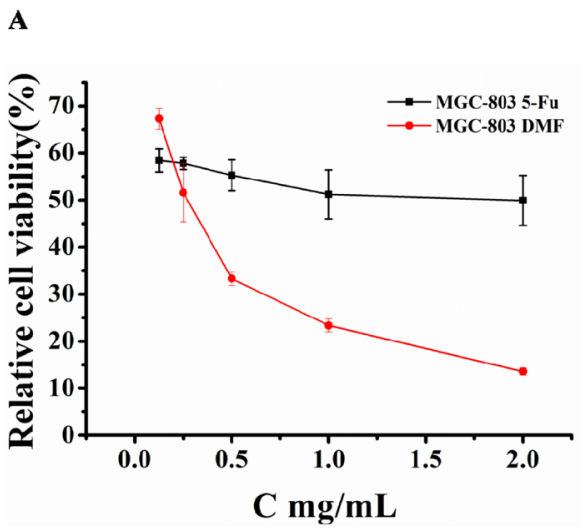

in cells. ${ }^{3)}$ However, the reason for significant lethal effect of DMF may be its strong transporting and targeting effect compared to $5-\mathrm{Fu}^{6}{ }^{6}$ In order to determine the appropriate dose of drug intervention to collect relevant biochemical indicators, this paper firstly implemented a study on the dose-dependent manner and time-dependent manner of 5-Fu and DMF intervention in MGC-803, respectively. 5-Fu and DMF can inhibited cell proliferation of MGC-803 in a concentration-dependent manner after $24 \mathrm{~h}$. The imparity of cell viability stimulated by $5-\mathrm{Fu}$ was $6.28-10.76 \%$ between the maximum and the minimum concentration, while the DMF made a difference of 52.95-54.92\% (Fig. 1A). The $\mathrm{IC}_{50}$ of DMF and 5-Fu were 263.1 and $1876 \mu \mathrm{g} / \mathrm{mL}$. In addition, 5-Fu and DMF inhibited cell proliferation in a time-dependent manner, respectively. The data demonstrated that DMF exert more potent effect of suppressing proliferation than 5-Fu against MGC-803 cells (Fig. 1B).

We have detected the toxicity of MLDH on A549, SGC-7901 and SKOV3 in time-dependent manner and concentration-dependent manner ${ }^{3}$ in the previous study. Our results reflected that the particularity (anti-cancer benefits) of the DMF preparation was a combination effect of 5-Fu and delivery system (MLDH) rather than the simple weighting of 5-Fu and carrier cytotoxicity. ${ }^{6}$

DMF Caused Obvious Morphological Characteristics of Distension Death in MGC-803 Cell morphology is one of the most direct ways to identify the type of cell death. The cell morphology was intact, and the mitochondria and endoplasmic reticulum were clear in the control group. There was chromatic agglutination $(\xi)$, which was characteristic of apoptosis after 5-Fu stimulation for $4 \mathrm{~h}$ (Fig. 2). Therefore, the cell death form induced by $5-\mathrm{Fu}$ can be defined as apoptosis. The majority of literatures indicated that $5-\mathrm{Fu}$ can induce apoptosis in many cancer cells, such as MGC-803, HCT116, MDA-MB -231, ${ }^{14-16)}$ which is consistent with our result. Cells were damaged severely, cellular and nuclear swelling after $4 \mathrm{~h}$ of DMF administration as shown in Fig. 2. There were numerous vacuoles free of organelle $(\triangle)$ in cell, cell contents were released from the edge of the cell membrane, and even whole cell was ruptured. Furthermore, lysosomes were highly activated during DMF intervention (O). The above results suggested that cellular structure severely damaged by DMF after a short period of time $(4 \mathrm{~h})$, which was highly consistent

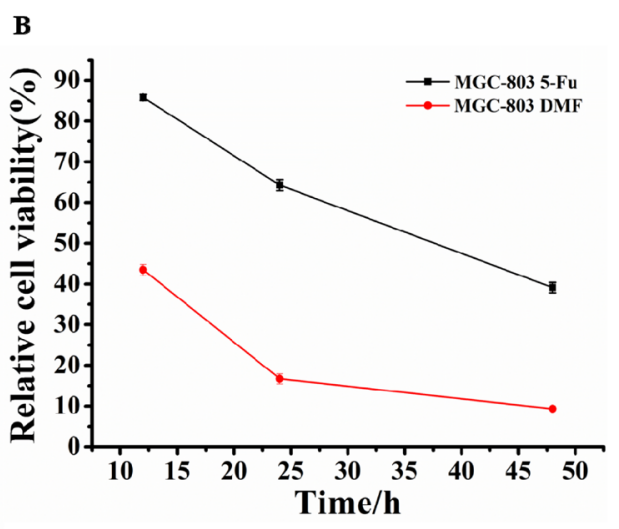

Fig. 1. Effect of Drug Intervention on Proliferation Activity of MGC-803 Cells in Vitro

(A) The cells having grown for $24 \mathrm{~h}$ were exposed to a full range of concentrations of $125,250,500,1000$, and $2000 \mu \mathrm{g} / \mathrm{mL}$ for 5 -Fu and $\mathrm{DMF}$, respectively. (B) The cells were exposed to $350 \mu \mathrm{g} / \mathrm{mL} 5$-Fu and $1 \mathrm{mg} / \mathrm{mL}$ DMF for 12,24 , and $48 \mathrm{~h}$, respectively. Cell viability was assessed by staining with CCK-8 for $2 \mathrm{~h}$. Data were shown as means \pm S.D. of at least triplicate determinations. Each experiment was performed in three replicate wells. (Color figure can be accessed in the online version.) 

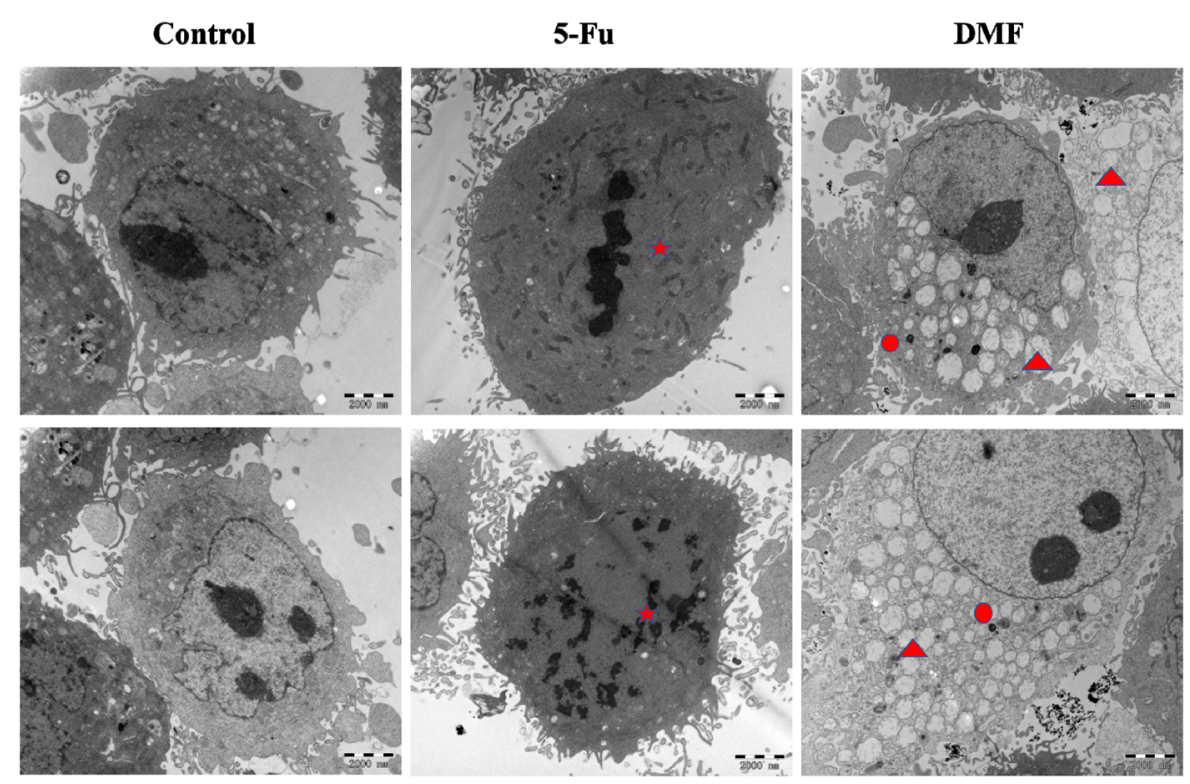

Fig. 2. Transmission Electron Microscopy (TEM) Show the Characteristics of Oncosis (Vacuoles Free of Organelle, $\triangle$ ) and Apoptosis (Chromatic Agglutination, $\succsim$ ) in MGC-803 Cells When Treated with 5-Fu Concentrations of $350 \mu \mathrm{g} / \mathrm{mL}, 1 \mathrm{mg} / \mathrm{mL}$ for $4 \mathrm{~h}$, Respectively

The lysosomal activity can be clearly observed $(\bigcirc)$ after DMF intervention. (Color figure can be accessed in the online version.)

with the morphology of swelling death. In other words, DMF changed cell death pattern of 5-Fu from apoptosis to oncosis.

DMF Induced ATP Depletion, MMP Decrease, ROS Accumulation and UCP-2 Activation in MGC-803 The supply and consumption of ATP can reflect the balance of intracellular energy during programmed cell death. The occurrence of apoptosis expend energy, the form of cell death will turn from apoptosis into oncosis as the result of energy insufficient. ${ }^{17)}$ According to Fig. 3A, ATP level was slight decreased after $5-\mathrm{Fu}$ treatment compared with control, and even exceed control at $48 \mathrm{~h}$. The possible reason is that cells damaged and exhibited some characteristics of apoptosis, such as ATP consumption in early. Cells continue multiplying and growing later, causing energy rising due to the limited dose to MGC-803. Nevertheless, there was a dramatic reduction in DMF treatment that ATP level reached $-0.59 \pm 0.067$ at $12 \mathrm{~h}$. The abnormal phenomenon implied a novel form of cell death induced by DMF, which distinct from apoptosis. According to ATP level, the form of cell death caused by DMF was similar to characteristics of oncosis. As documented that the ATP level plays an important role in cell death, which determine how the cell dies. ${ }^{11,17)}$

Mitochondrial dysfunction is one of the important features of programmed cell death (PCD). The loss of MMP and the opening of membrane permeability transition pore (PTP) related to cell death closely. The intracellular ROS accumulation and MMP loss were caused with opening of the PTP, eventually triggering cell death when cells are in an unfavorable environment. ${ }^{18)}$ The decrease of MMP was observed in timedependent manner according to a fluorescence change from red to green after 5-Fu and DMF exposure, respectively (Fig. $3 \mathrm{~B})$. The literature reported that mitochondrial dysfunction is a common feature of cell death (whether apoptotic or oncosis), which caused the loss of MMP. ${ }^{19,20)}$ However, the loss of MMP induced by DMF showed more pronounced effect compared with 5-Fu.

Mitochondrion is source of ROS, and its accumulation can damage the mitochondrial membrane in turn. To investigate the difference of ROS in treatment of 5-Fu and DMF to MGC-803, respectively, flow cytometry was proceed with DCFH. After treated with 5-Fu, a significant increase of DCFH signal illustrated the over-generation of ROS in timedependent manner, which consistent with the JC-1 results (Fig. 3C). Whereas, it was distinct that the level of ROS remained unchang in DMF, which suggested that cell death was ROSindependent pathway in triggering mitochondrial dysfunction.

The study suggested that the mechanism of cell death by $5-\mathrm{Fu}$ induction might relate to the conventional mitochondrial apoptotic pathway according to ROS accumulation. ${ }^{21)}$ Obviously, mitochondrial dysfunction was not main factor for DMF to induce oncosis although there were MMP decrease and ATP depletion. Some chemotherapeutic drugs or preparations may cause mitochondrial dysfunction such as ATP depletion, MMP decrease when they induce cell oncosis, but not exist ROS accumulation to trigger cell death through mitochondrial dysfunction pathway. ${ }^{22)}$

Uncoupling protein-2 (UCP-2) is a proton transporter on the mitochondrial inner membrane that mediates proton leakage, affects energy metabolism, ROS accumulation, apoptosis and oncosis of tumor cells. ${ }^{23,24)}$ To investigate whether UCP-2 was involved in MGC-803 cells stimulated by $5-\mathrm{Fu}$ and DMF, respectively, we detected the expression of UCP-2 protein with Western blotting. The result revealed that the level of UCP-2 was decreased in time-dependently manner after 5-Fu and DMF intervention (Fig. 3D). In our results, the decrease of UCP-2 was more significant than 5-Fu after DMF intervention at $24 \mathrm{~h}$, but its decrease caused by 5 -Fu intervention was more obvious than DMF at 2-8h (Fig. 3D). The literature shown that there are different invasion results of mitochondria and lysosomes by certain drugs or factors. ${ }^{25}$ The result of TEM showed that the lysosome is extremely active with DMF intervention compared to 5-Fu in MGC-803. We suspected that DMF might first invade the lysosome, and 5-Fu attack mitochondria, which may be a reason that caused the above 

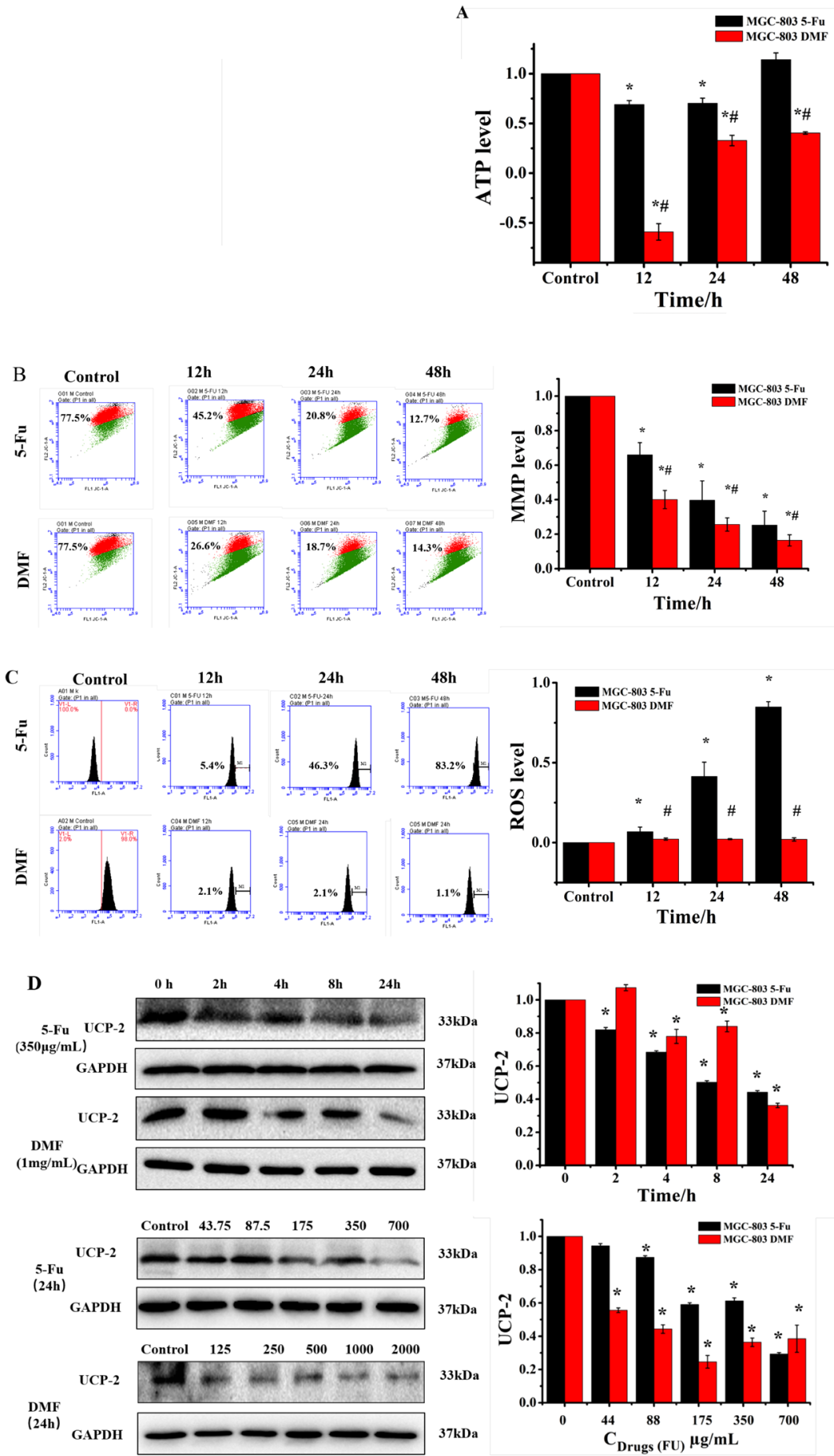

Fig. 3. The Level of ATP, MMP and ROS Were Detected for MGC-803 Cells after Treatment with $350 \mu \mathrm{g} / \mathrm{mL} 5$-Fu and $1 \mathrm{mg} / \mathrm{mL}$ DMF for 12,24 , and $48 \mathrm{~h}$, Respectively

(A) The level of ATP. (B) The level of MMP (dependent mitochondria dye JC-1 (red)). (C) The level of ROS. (D) Effect of drug intervention on UCP-2 protein of MGC-803. GAPDH, loading reference. Annotation: DMF contains $35 \%$ of 5-Fu, and "C $\mathrm{C}_{\mathrm{Drugs}} \mathrm{FU}$ " represents equal doses of 5-Fu and DMF preparations in dose course of Western blot. *Denotes $p<0.05$ vs. control; \# Denotes $p<0.05$ DMF $v s$. 5-Fu. Data were shown as means \pm S.D. of at least triplicate determinations. Each experiment was performed in three replicate wells. (Color figure can be accessed in the online version.)

results. In other words, the time that DMF escapes from lysosomes and acts on mitochondria may be $8-24 \mathrm{~h}$, which was longer that directly acted on the mitochondria than 5-Fu. The dose-effect relationship demonstrated that DMF was more effective in different doses at the same sufficient time (24h), but the long-term effect of high dose 5-Fu would exceed that of DMF. It is required to research in our further study (Fig. 3D).

The literature reported that UCP-2 down-regulation, ROS accumulation and apoptosis were inhibited if some signaling pathways are broken (such as c-Jun N-terminal kinase (JNK)) in anti-tumor of paclitaxel, ${ }^{26)}$ which suggested that 5 -Fu and paclitaxel may have similar apoptosis pathway. The decrease degree of ATP and UCP-2 were more significant in DMF-induced cell death compared with 5-Fu without change of ROS, which showed that the mechanism was obviously different from that of 5-Fu. In other words, one of the difference was 
whether exist the correlation between UCP-2 and ROS levels in the mechanism of cellular oncosis and apoptosis.

UCP is a mitochondrial inner membrane protein that eliminates the difference of transmembrane proton concentration on both sides of membrane, which can relieve the oxidative phosphorylation process, blocking ATP production. Some chemicals (such as thyroxine) are called as uncoupler, can promote the expression of UCP to make UCP-2 protein complete the process of uncoupling, increasing heat production and oxygen consumption. They can also consume ATP by increasing the ionic pumps on the cell membrane to promote the progress of the oxidative phosphorylation. ${ }^{27)}$

Based on the above illustration, we considered that as an uncoupler, DMF activate the UCP-2 to hinder output of ATP. DMF may also plays a similar role just as in thyroxine, increasing ATP consumption and promoted oxidative phosphorylation by the amount of sodium potassium pump on the cell membrane, while ROS levels remain unchanged. Significantly, the change of ATP related to the activation of UCP-2 in apoptosis and oncosis, but it was uncertain whether ROS accumulation triggered by ATP depletion in oncosis.
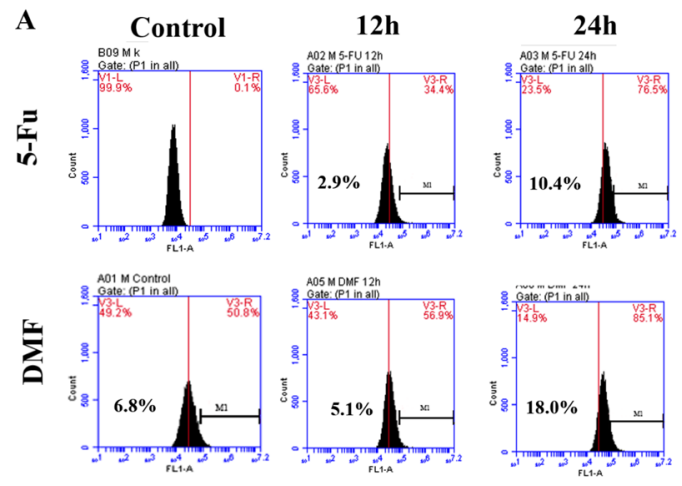

B
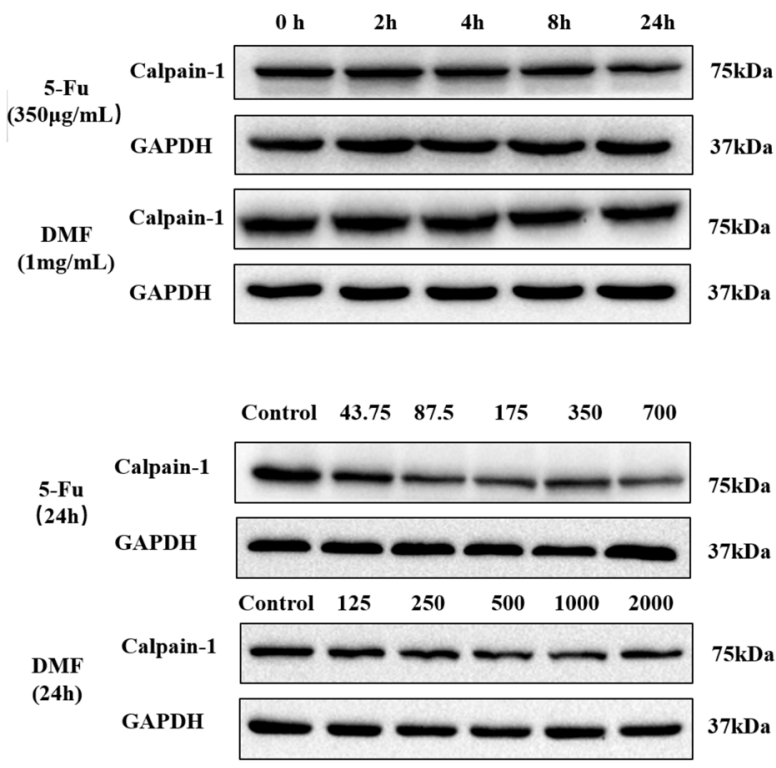

DMF Induced $\mathrm{Ca}^{2+}$ Elevation and the Activation of Calpain-1 There are high levels of $\mathrm{Ca}^{2+}$ in endoplasmic reticulum and the mitochondria, they are called intracellular "calcium banks." The elevation of $\mathrm{Ca}^{2+}$ is an ordinary feature of cell death (either apoptosis or oncosis). ${ }^{28)}$ To explore the level of $\mathrm{Ca}^{2+}$ in MGC-803 of DMF exposure, we used Flu-AM as a fluorescent probe to detect $\mathrm{Ca}^{2+}$ by flow cytometry. Figure $4 \mathrm{~A}$ showed that $\mathrm{Ca}^{2+}$ displayed an increase in time-independent manner with 5-Fu and DMF compared with control in MGC-803 cells. The elevation of $\mathrm{Ca}^{2+}$ induced by DMF was higher than $5-\mathrm{Fu}$ before $24 \mathrm{~h}$. However, the increase rate of $\mathrm{Ca}^{2+}$ was significantly higher than DMF treatment in the 5-Fu at $48 \mathrm{~h}$. The above result indicated that mitochondrial dysfunction or endoplasmic reticulum stress (ERS) caused by DMF were gradually aggravated in time-dependent manner. The change of $\mathrm{Ca}^{2+}$ may be related to organic injury and activation of related protein in mitochondria and endoplasmic reticulum due to drug intervention.

The MMP is an important indicator for the mitochondrial function. The decrease of MMP and the opening of PTP are closely related to apoptosis. The results demonstrated that
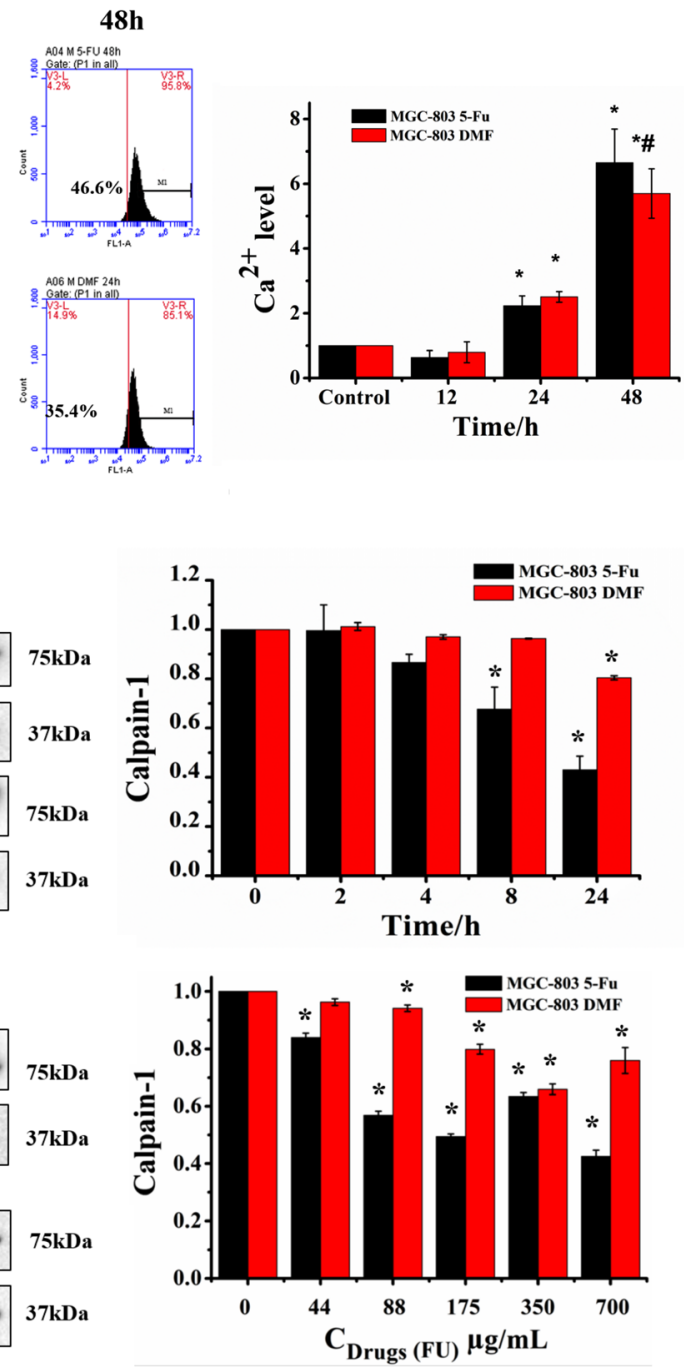

Fig. 4. (A) The Level of $\mathrm{Ca}^{2+}$ Was Detected with Fluo-3AM for MGC-803 Cells after Treatment with $350 \mu \mathrm{g} / \mathrm{mL} 5-\mathrm{Fu}$ and $1 \mathrm{mg} / \mathrm{mL}$ DMF for 12,24 , and $48 \mathrm{~h}$, Respectively; (B) Effect of Drug Intervention on Calpain-1 of MGC-803

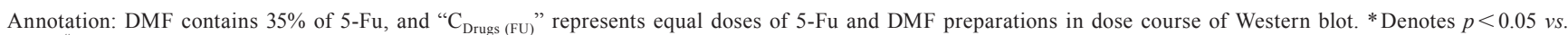
control; ${ }^{*}$ Denotes $p<0.05$ DMF vs. 5-Fu. Data were shown as means \pm S.D. of at least triplicate determinations. Each experiment was performed in three replicate wells. (Color figure can be accessed in the online version.) 
ATP and MMP were decreased after 5-Fu and DMF intervention, while the effect of DMF was more significant than $5-\mathrm{Fu}$ in our study. It was confirmed that ATP insufficient was one of the reason in oncosis. ${ }^{11,17)}$ At the same time, the result of DMF in our study had fully verified the common phenotype of oncosis. In the process of apoptosis, some chemotherapeutic agents cause ATP decrease, ROS accumulation, $\mathrm{Ca}^{2+}$ elevation and MMP loss. Cytochrome $C(\mathrm{Cyt} C)$ released from the PTP, while lead to apoptosis. It is completely consistent with the common mechanism of apoptosis after 5-Fu stimulation. The oncosis is also related with mitochondrial membrane permeability transition. ${ }^{29)}$ However, the mechanism of DMF treatment was not fully complied with it due to ROS unchanged, which indicated the mechanism of DMF-induced cell death was different from pre-existing mechanism, and mitochondrial pathway was not the main mechanism of oncosis induced by DMF.

Calpain, a calcium-activated protease family, is regarded as one of the iconic proteins in the procedure of cell death, ${ }^{12)}$ and it can be activated if $\mathrm{Ca}^{2+}$ is released from the "calcium bank." The change of calpain-1 was detected with Western blotting. Figure 4B indicated that there was not a significant dose-dependent after $24 \mathrm{~h}$ with DMF exposure. The increased degree of $\mathrm{Ca}^{2+}$ was weakened compared with 5-Fu after $48 \mathrm{~h}$ of DMF exposure according to our results, and the level of calpain-1 was regulated by $\mathrm{Ca}^{2+}$. Therefore, calpain-1 did not show dose-dependent, the reason may be that the increased degree of $\mathrm{Ca}^{2+}$ was slowed after $2000 \mu \mathrm{g} / \mathrm{mL}$ DMF simulation, which caused that the level of calpain-1 was changed with doses, although it was still lower than that of the control group. Furthermore, there was not a clear decrease in timedependent manner.

The literature indicated that there was not only the destruction of the cytoskeleton, but also plasma membrane injury in mitochondrial dysfunction caused by calpain activation. ${ }^{29)}$ Our results suggested that the decrease of calpain-1 did not show a clear time-dependent manner in early, and the autolysis of calpain-1 was not observed in MGC-803 intervened by DMF. Nevertheless, the down-regulation of calpain-1 was significant in 5-Fu compared with DMF, which suggested that the calpain-1 was susceptible to DMF, but its consumption and autolytic degradation was unclear. Therefore, we speculate that the mainly hydrolytic damage effect in MGC-803 intervened by DMF may not be the calpain system, but likely to be closely related to the lysosomal/autophagy mechanism.
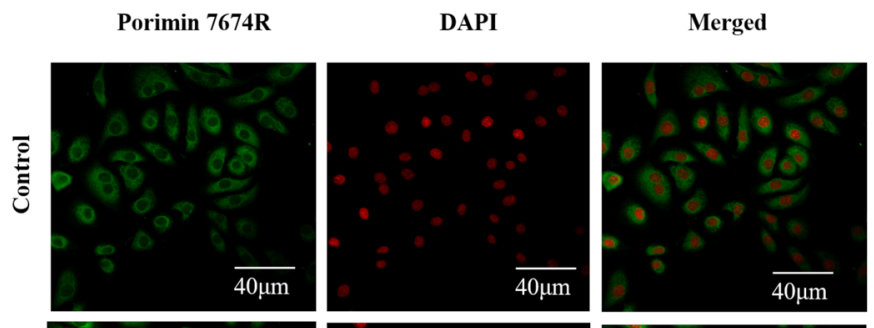

Enlarged
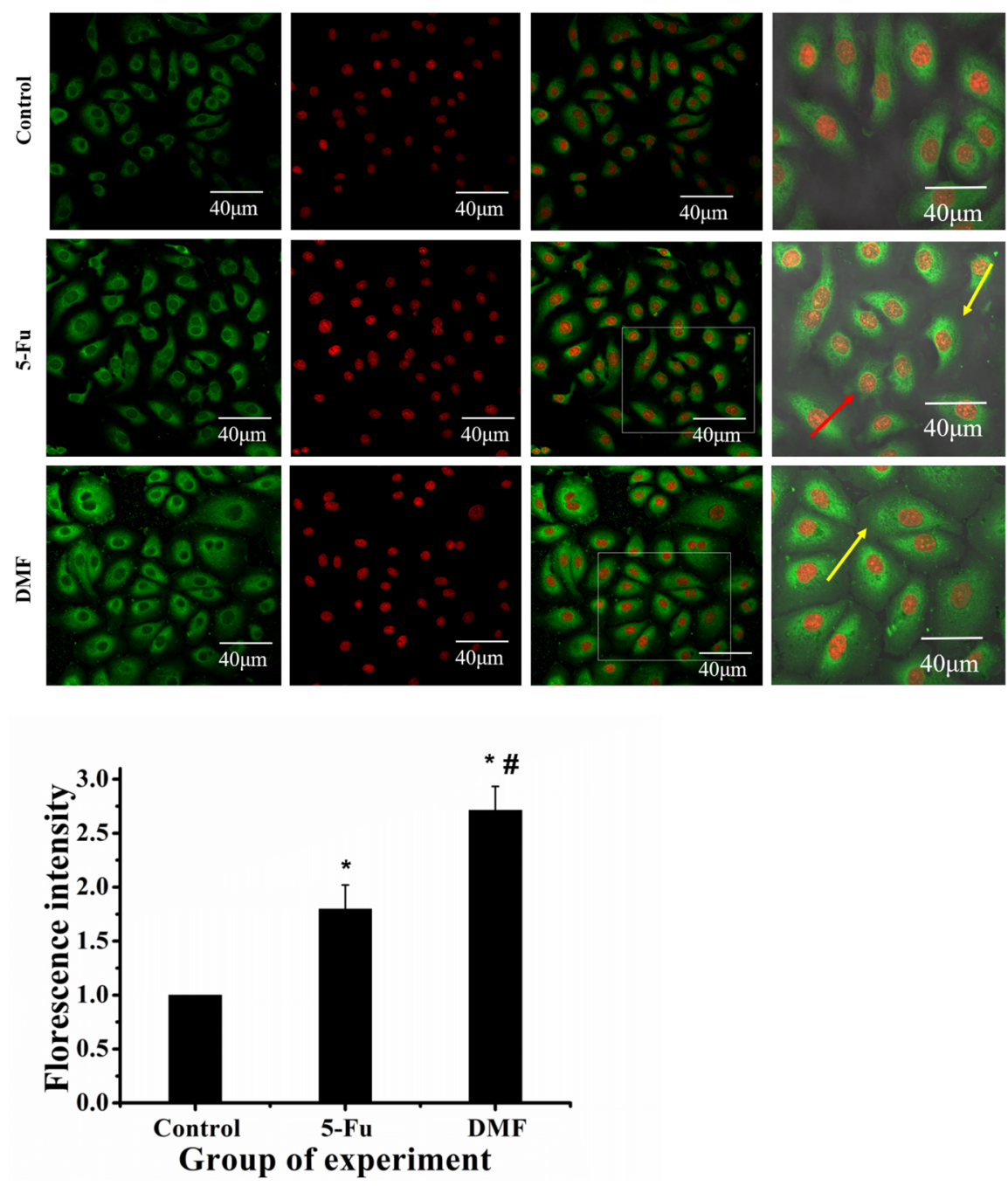

Fig. 5. The Result of Porimin Using Immunocytochemistry Assay by Confocal Microscopy (40×)

*Denotes $p<0.05$ vs. control; ${ }^{\#}$ Denotes $p<0.05$ DMF vs. 5-Fu. Data were shown as means \pm S.D. of at least triplicate determinations. (Color figure can be accessed in the online version.) 
DMF Induced Membrane Injury in MGC-803 The porimin (pro-oncosis receptor inducing membrane injury) is regarded to be responsible for the abnormal membrane permeability, which directly causes the cell swelling. The activation of porimin is also a marker of oncotic cell death. ${ }^{30)}$ Meanwhile, the change of cell shape and volume also imply a profound impact on apoptosis and oncosis. The result showed that porimin was located around the nucleus after $5-\mathrm{Fu}$ and DMF exposure for $24 \mathrm{~h}$. The fluorescence intensity was gradually increased under the parameters on basis of DMF (Control $<5-\mathrm{Fu}<\mathrm{DMF}$ ). According to the cell morphology, cell shrink (" $\rightarrow$ ") and membrane permeability increase (" $\rightarrow$ ") were observed after 5-Fu stimulation, which was consistent with morphology of apoptosis. There were signally swelling, and membrane permeability increase in MGC-803 cell treated with DMF (Fig. 5).

The activated porimin was located in the cell membrane in oncosis. ${ }^{31)}$ Our data showed that porimin is situated around the nucleus instead of the cell membrane in MGC- 803 cells stimulated by DMF. It is evident the activation of porimin also mediates the formation of pores in the plasma membrane followed by cell oncosis. The results of TEM and the above result suggested that the way of cell death induced by $5-\mathrm{Fu}$ is apoptosis. Nevertheless, we speculate the activation of porimin also imply that $5-\mathrm{Fu}$ may have the potential to transform the manner of cell death from apoptosis to oncosis for MGC-803 cell if the time of intervention is long enough. It is required to research in our further study.

The expression of porimin also regarded as a direct evidence to prove cell oncosis apart from ATP insufficient. The activation of the membrane protein can damage cell membrane structure and cause dysfunction. A significant increase of membrane permeability caused exhaustion of the ion pump function on the membrane, followed by water and sodium ions flock into cells, eventually swelling and rupture leading to oncosis. $^{32)}$

DMF Induced Some Apoptotic Phenotypes in MGC-803 Cysteinyl aspartate specific protease (caspase) is the product
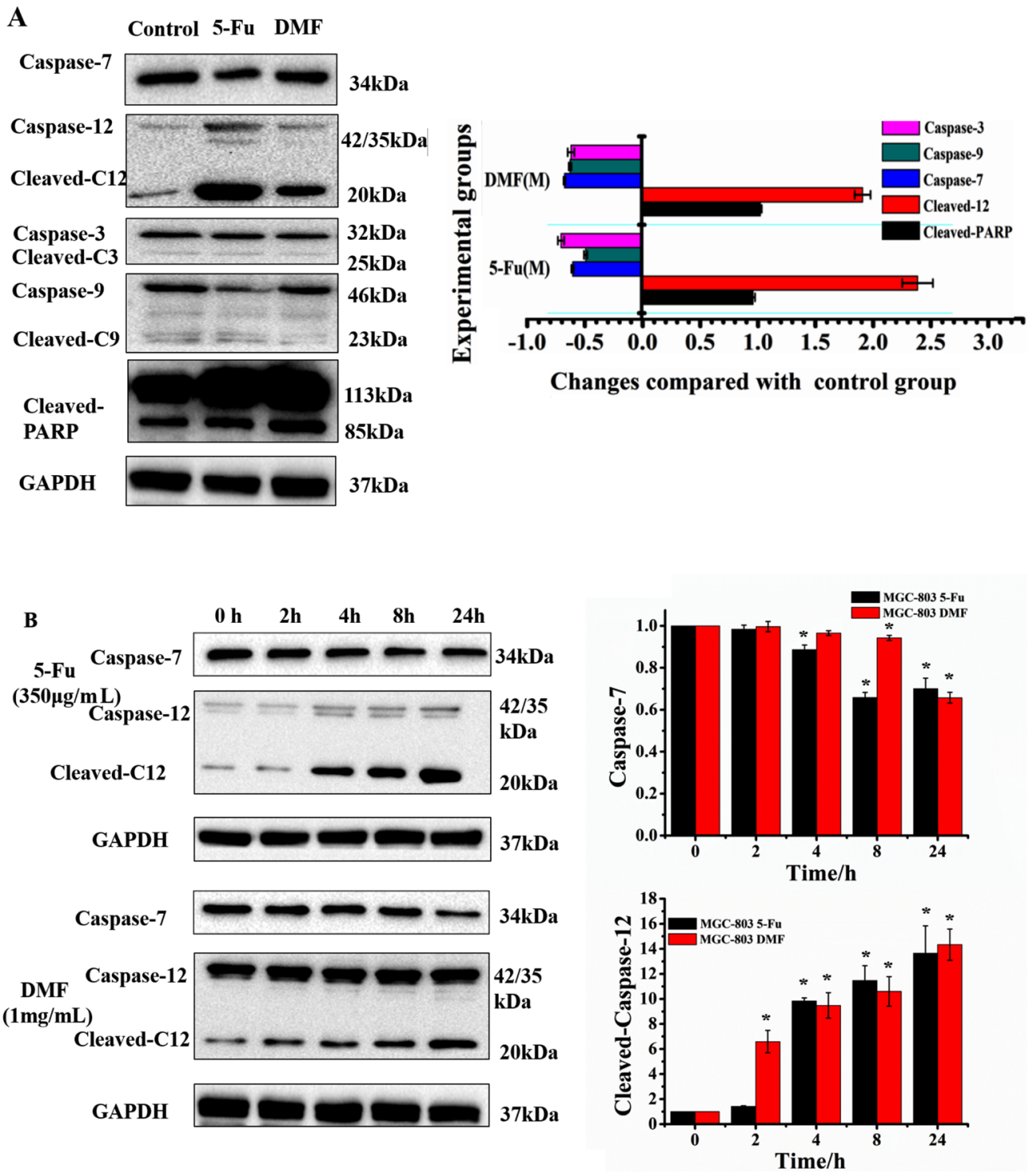

Fig. 6. (A) The Level of Caspases-3, -7, -9, and -12, PARP Were Detected When Cells Were Exposed to $350 \mu \mathrm{g} / \mathrm{mL} 5-\mathrm{Fu}$ and $1 \mathrm{mg} / \mathrm{mL} \mathrm{DMF}$ for $24 \mathrm{~h}$ by Western Blotting; (B) The Level of Caspases-7, and -12 Were Detected in Time-Dependently

* Denotes $p<0.05 v s$. control. Data were shown as means \pm S.D. of at least triplicate determinations. Each experiment was performed in three replicate wells. (Color figure can be accessed in the online version.) 
of gene family, including a pentapeptide structure containing cysteine that cleaves the substrate at the N-terminal aspartate residue. Thereby, it can regulates the apoptosis by activation or inactivation of the substrate. 5-Fu is a classical anti-cancer drug that induces apoptosis in cancer cells. The mechanism of apoptosis mainly include endogenous mitochondrial pathway, Bcl-2 anti-apoptotic family protease-mediated apoptosis and exogenous pathways mediated by caspase- 8 and ligand Fas- associating protein with a novel death domain (FADD). ${ }^{33)}$

As development of ERS research, activation of caspase-12 also gets increasingly attention. So far, three pathways have been found to activate caspase-12, including the inositol-requiring enzyme 1 (IRE1) pathway, ${ }^{34)}$ the $m$-calpain pathway, ${ }^{35}$ ) and the caspase-7 pathway, ${ }^{36}$ all of them are associated with ERS. Caspase-12 is only present on the endoplasmic reticulum membrane in the caspase family, and considered as a key
A

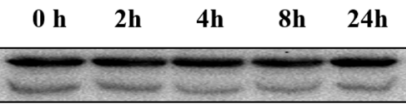

Caspase-3
Cleaved-C3
Caspase-9

Cleaved-C 9

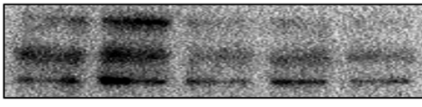

5-Fu

$(350 \mu \mathrm{g} / \mathrm{mL})$ Cleaved

-PARP

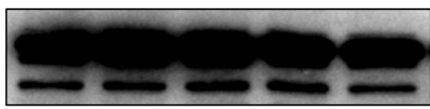

GAPDH
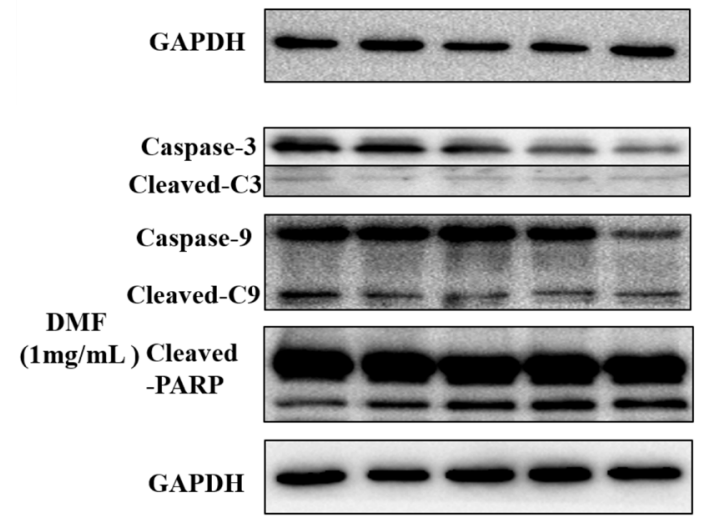

$37 \mathrm{kDa}$

32kDa

25kDa

46kDa

$23 \mathrm{kDa}$

$113 \mathrm{kD}$

$85 \mathrm{kDa}$

$37 \mathrm{kDa}$

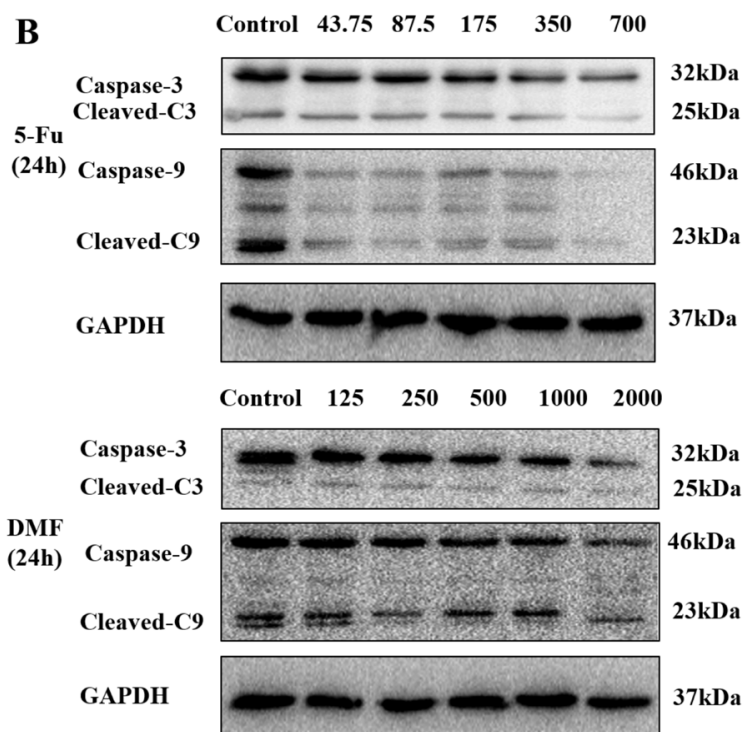

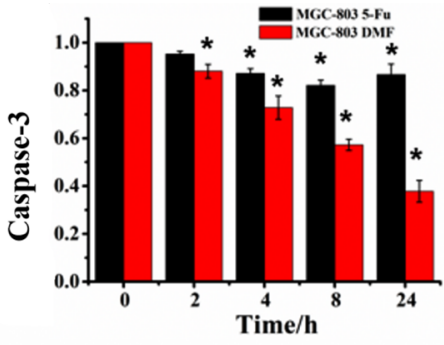
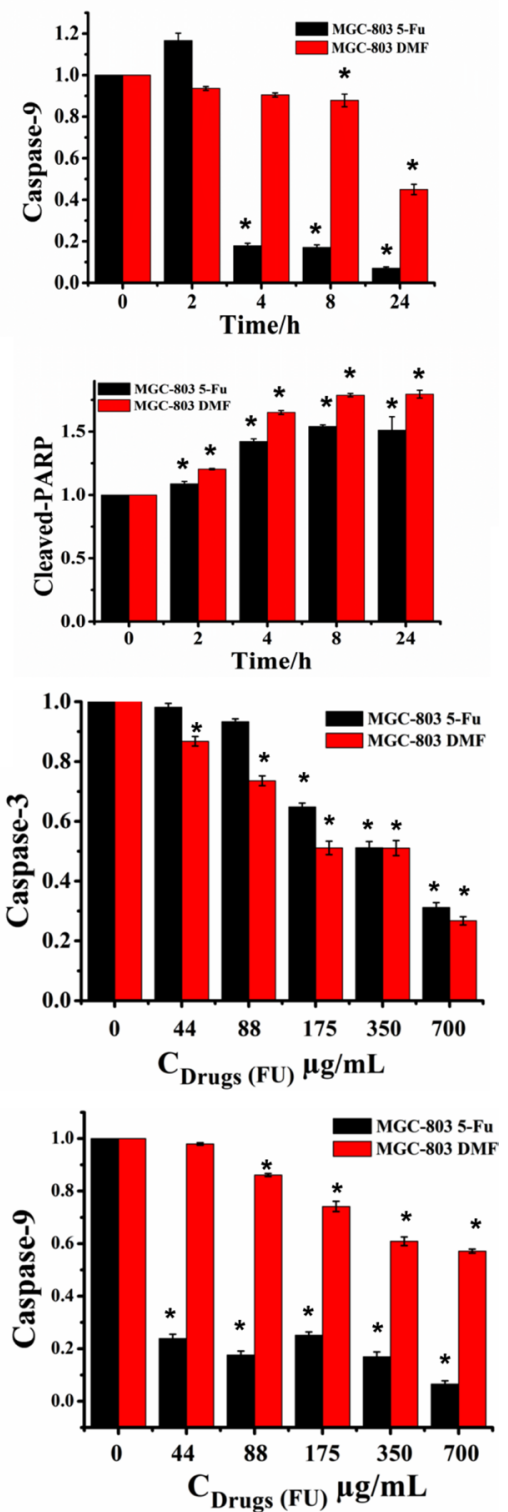

Fig. 7. The Level of Caspases-3, and -9, PARP Were Detected When Cells Were Exposed to 5-Fu and DMF by Western Blotting to Indicate Time (A) and Indicate Concentration (B), Respectively

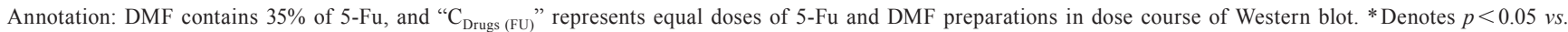
control. Data were shown as means \pm S.D. of at least triplicate determinations. Each experiment was performed in three replicate wells. (Color figure can be accessed in the online version.) 
molecule that mediates ERS-induced apoptosis. ${ }^{37)}$ The study suggested that caspase-7 was activated and migrated to the endoplasmic reticulum membrane, accompanied with cleave of the caspase-12 in ERS, activating downstream caspase and resulting in cell apoptosis. ${ }^{36)}$ Caspase-7 can cleave the Asp-94 region of pro-caspase-12, which produce caspase-12 of $42 \mathrm{kDa}$. Two small fragments of 20 and $10 \mathrm{kDa}$ were formed by self-cleave after a matter, in which caspase- 12 of $42 \mathrm{kDa}$ continued to self-cleave to form $35 \mathrm{kDa}$ of caspase- 12 in the Asp-341 region. ${ }^{36)}$ Activated caspase-12 directly activates caspase-9, following cleave caspase-3 to act on poly ADP-ribose polymerase (PARP) and other substrates, eventually result in cell apoptosis.

We detected the expression of caspases-7, -12, -9 and -3 during 5-Fu and DMF exposure using Western blot, respectively. The decrease of caspase-7 was shown in time-dependent in MGC-803. Furthermore, the activation and cleavage of caspase-12 (20 kDa) shown time-dependent increasing trend (Fig. 6B). The activation and cleaved of caspases-3, -9 (25 and $23 \mathrm{kDa}$ ) were observed with 5-Fu and DMF exposure in timeand dose-corresponding manner (Figs. 7A, B). Meanwhile, PARP protein was cleaved $(85 \mathrm{kDa})$ (Fig. 6A). Moreover, DMF was more sensitive for caspase-3 and PARP protein (Fig. 6A). The result in our study suggested that caspase-7 cleaved caspase-12 to $20 \mathrm{kDa}$ in ERS.

We examined the activation of caspase-7, but there did not appear the band of cleaved-caspase-7 in the region after $34 \mathrm{kDa}$ in our experiment (cleaved-caspase-7 should appear at $20 \mathrm{kDa}$ ). Based on the corresponding relationship between the decrease of caspase- 7 and the accumulation of cleaved caspase-12, we speculate that consumption of caspase-7 may also be one of the reasons for the activation of caspase- 12 . In other words, there were obvious ERS response and cleavage of caspase-12 in the process of cell death induced by
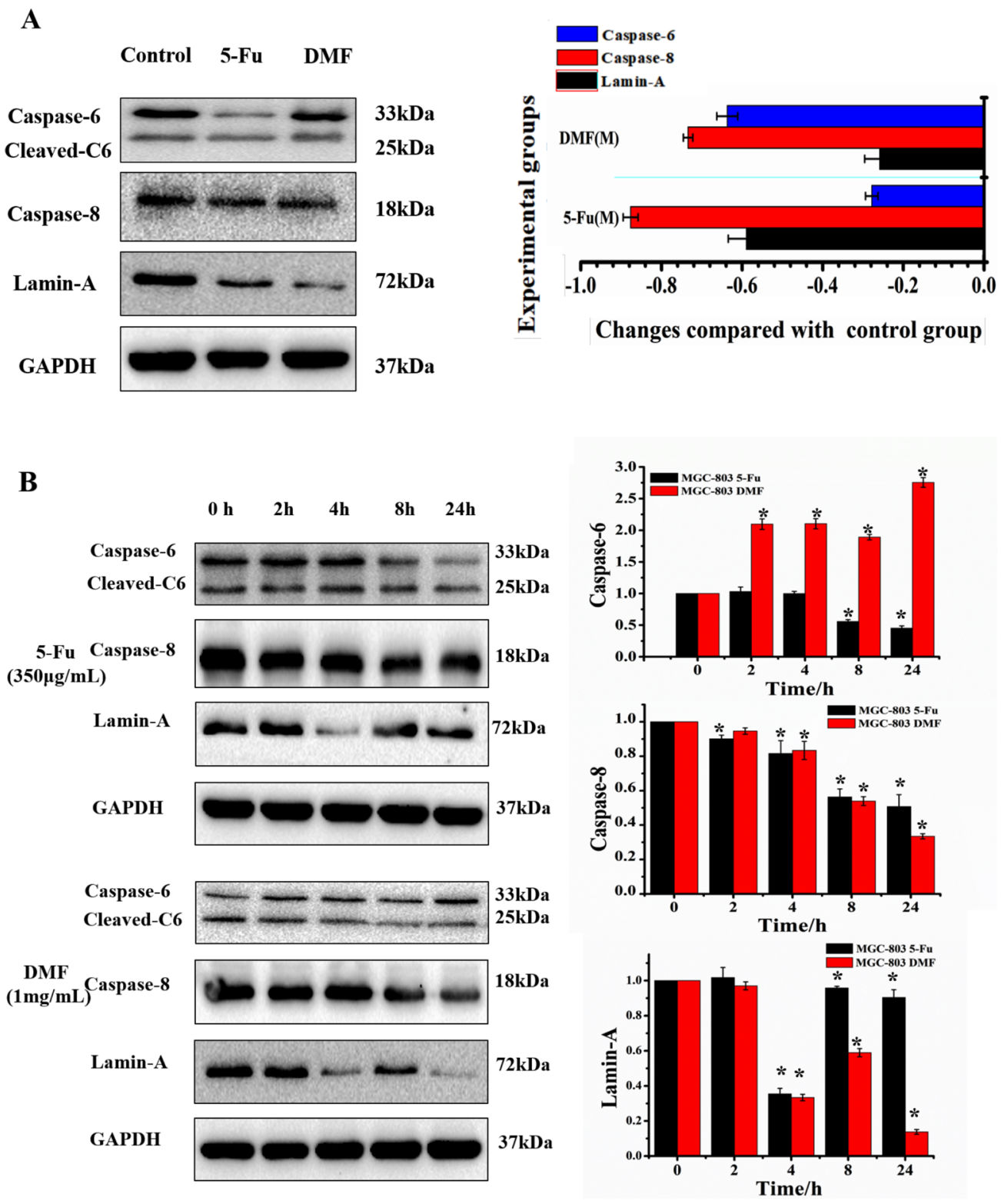

Fig. 8. (A) The Level of Caspases-6, -8, Lamin-A Were Detected When Cells Were Exposed to $350 \mu \mathrm{g} / \mathrm{mL} 5$-Fu and $1 \mathrm{mg} / \mathrm{mL}$ DMF for $24 \mathrm{~h}$ by Western Blotting; (B) Expression of Caspases- 6 and -8, and Lamin-A for Indicate Time in Indicating Concentration, Respectively

*Denotes $p<0.05 v s$. control. Data were shown as means \pm S.D. of at least triplicate determinations. Each experiment was performed in three replicate wells. (Color figure can be accessed in the online version.) 
DMF, but the activated mechanism of caspase-12 was more specific. Caspase-7 can be migrated to the endoplasmic reticulum membrane, consuming and activating caspase-12, but the cleavage of caspase-7 was not necessarily observed. The possible reason may be that the generation and consumption of cleaved-caspase-7 is too fast to detect its accumulation during the activation of caspase-12. Another possibility, caspase-12 could just be activated with caspase-7. All these speculations need to prove in our subsequent experiments.

The mature caspase-12 was formed, directly activating caspase-9 to cleave caspase-3, followed by cleaving the PARP and ultimately leading to apoptosis. Apoptosis is also associated with release of apoptotic factors (such as Cyt $C$ ) in mitochondria. The apoptotic complex was generated through combination between Cyt $C$ and Apaf1 in cytoplasm, which can activates pro-caspase-9, causing the activated caspase-9 to cleave caspase-3, further leading to cleavage of PARP and apoptosis. ${ }^{38)}$ On one hand, the change of caspases-7, -12 , and -9 were located on a lesser extent than $5-\mathrm{Fu}$, which was inconsistent with $\mathrm{Ca}^{2+}$ increase and activation of calpain-1 triggered by DMF. On the other hand, the results indicated that the activation and cleavage of caspase- 3 and the PARP were more significant than 5-Fu, which suggested that the potent ERS effect was induced by DMF, and the initial factor that induced ERS was distinct from 5-Fu.

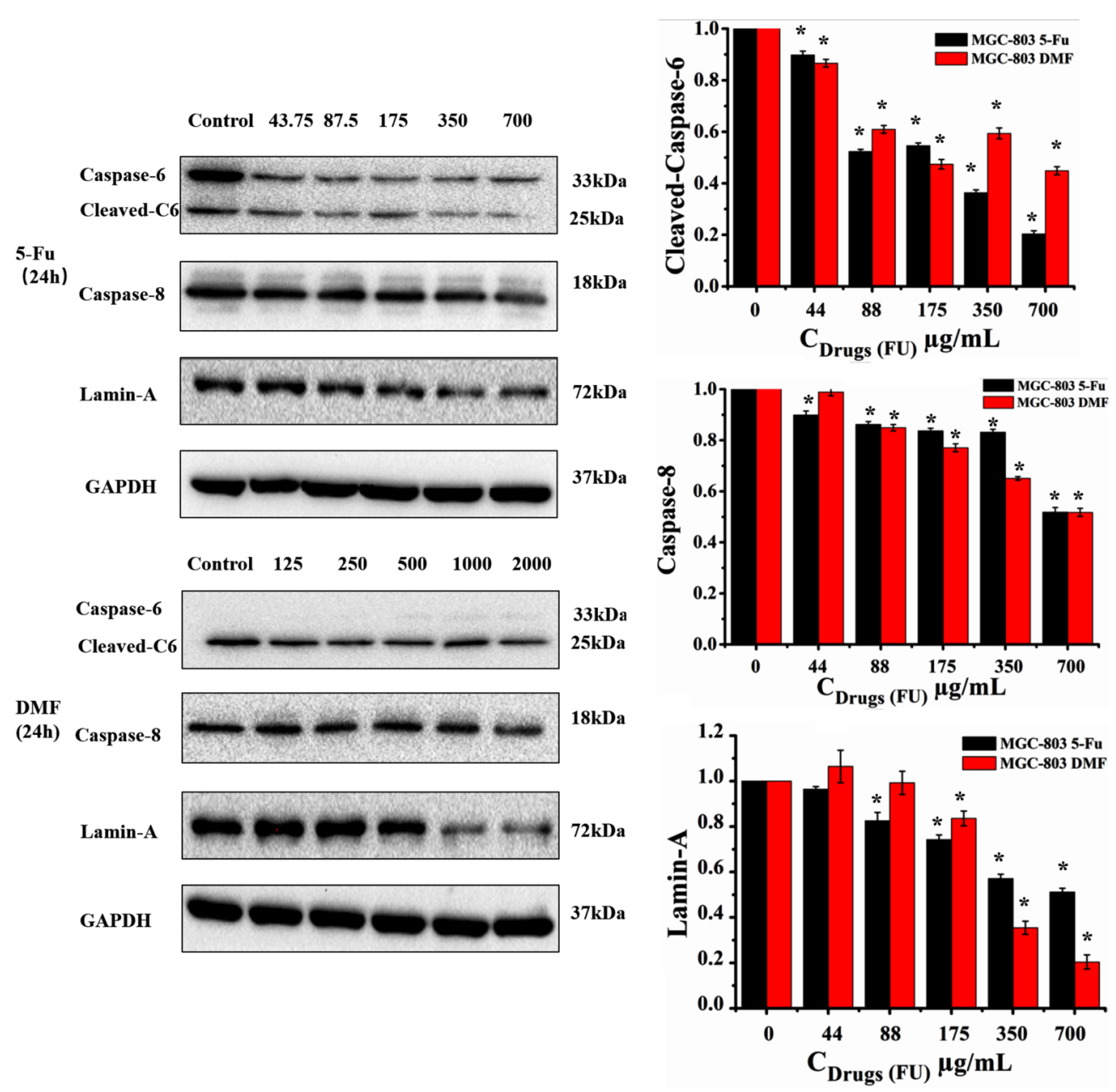

It is well known that there is a relationship of caspase cascade between caspases-3 and $-9 .{ }^{39)}$ According to decrease of caspases- 9 and -3 , we can suggest that caspases- 9 and -3 can be activated by the intervention of both $5-\mathrm{Fu}$ and $\mathrm{DMF}$, and there was a clear relationship of caspase cascade between caspases-9 and -3 . However, there were significant differences in the level of caspases- 9 and -3 . Specifically, the decrease of caspase- 3 was more significant than $5-\mathrm{Fu}$ in DMF. while, the decrease of caspase- 9 was obvious compared with DMF in $5-\mathrm{Fu}$, which reflects that there are certain differences in the pharmacological mechanism between 5-Fu and DMF preparation. Possible reasons include the following. 5-Fu mainly induces the apoptosis of cancer cells through mitochondrial death pathway, during which caspase- 9 is activated with the apoptotic complex generated through combination between Cyt $C$ and Apaf1 in cytoplasm, the activation and consumption degree of caspase-9 is high. DMF may mainly induce oncosis through the lysosomal pathway in tumor cell, so activation of caspase- 9 can directly act on caspase- 3 , but the activation mechanism of caspase- 9 may be different from 5-Fu. In addition, other factors in the lysosomal pathway may also increase the degree of activation and consumption of caspase-3.

Caspase- 8 is a key "apoptotic initiator" in caspases family among the exogenous pathways mediated by death receptors (Fas, DR4 and DR5). The activated caspase- 8 can initiate the

Fig. 9. Expression of Caspases-6 and -8, and Lamin-A in Dose-Dependent Manner

Annotation: DMF contains $35 \%$ of $5-\mathrm{Fu}$, and " $\mathrm{C}_{\text {Drugs (FU) }}$ " represents equal doses of 5 -Fu and DMF preparations. $*$ Denotes $p<0.05$ s. control. Data were shown as means \pm S.D. of at least triplicate determinations. Each experiment was performed in three replicate wells. (Color figure can be accessed in the online version.) 
caspase cascade to further activate its downstream homologous enzymes, such as caspases- 6 , and -7 , etc., causing activation of caspase- $3{ }^{40)}$ Lamin-A plays an important role in maintaining the morphological structure of cells. ${ }^{41}$ ) The lamin-A will combine with activated caspase- 6 to trigger apoptosis due to it is a natural substrate for caspase-6. The research reported that caspase- 6 promoted cell apoptosis at least in part through the cleavage of lamin $\mathrm{A}^{42}$ )

The paper investigated the expression of caspases- $6,-8$ and lamin-A during drugs intervention. Figures $8 \mathrm{~B}$ and 9 showed that the levels of casapses- 6 and -8, and lamin-A were decreased compared with the control after 5-Fu and DMF treatment in dose corresponding manner, respectively. The level of lamin-A was recovered after a decline at $8 \mathrm{~h}$ in $5-\mathrm{Fu}$ and $\mathrm{DMF}$ exposure, which may be due to the compensatory effect of the self-protection mechanism in cells. Along with the extending of drugs intervening time, the self-protection mechanism was weakened, causing the level of lamin-A could not be recovered after $24 \mathrm{~h}$, and decreased urgently. The decrease of caspase- 8 and lamin-A was greater than 5-Fu in DMF (Fig. $8 \mathrm{~A})$. Caspase- 6 is the only protease that can markedly cleave of caspase- 8 in Cyt $C$ extractive. ${ }^{43)}$ Meanwhile, caspase- 8 can be evidently inhibited if suppress caspase- 6 by some measures in cells, which make caspase- 6 become a main activators for caspase- 8 . The literature reported that caspase- 6 could induce Cyt $C$, which further enhanced the caspase cascade effect. ${ }^{44)}$ Therefore, we can illustrate that there might be a complexity relation between caspases- 6 and -8 rather than certain link after DMF exposure, which may be a reason that expression level of caspase 6 and lamin-A were inconsistent, although lamin-A was a natural substrate for caspase-6. Beyond that, DMF was a nuclear-targeted drug according to the previous research. However, it is explicit that there is similar apoptosis pathway in 5-Fu and DMF, and the form of cell death may be changed from apoptosis to oncosis.

We believe that oncosis is more meaningful than apoptosis for chemotherapy of cancer cells, but it is necessary to control the side effects of DMF on normal tissues. Therefore, targeted therapy is necessary. DMF mainly induced oncosis in MGC-803 according to morphological analysis, and the $\mathrm{IC}_{50}$ of DMF was much smaller than $5-\mathrm{Fu}$, these suggested that DMF was more suitable as a chemotherapeutic agent compared with 5-Fu. Oncosis differs from apoptosis in both morphological changes and biochemical reaction mechanism, which has implications for diagnostics and pharmacological analysis. Furthermore, the cancer therapy-drug-resistance may be defeated in oncosis.

\section{CONCLUSION}

To conclude, DMF can trigger mitochondrial dysfunction, including ATP decrease, MMP reduction and $\mathrm{Ca}^{2+}$ elevation. Meanwhile, the rate of ATP depletion is predominantly different from $5-\mathrm{Fu}$, which is consistent with the mechanism of oncosis. DMF intervention does not show a noticeable effect on ROS levels. Therefore, we speculate that the endogenous mitochondrial apoptosis pathway may not be the main reason for DMF-inducing oncosis against MGC-803 cells.

DMF can induce strong ERS effect and exist some cascade reactions between caspases-7, -12 , -9 , and -3 , and PARP, which displays that there may be signaling pathways similar with apoptosis. The pre-oncosis receptor of cancer cells strongly is expressed in the intervention process of DMF, and the cell shows a morphological trait of oncosis. However, in view of the result of calpain-1, the hydrolytic damage of cell may be not brought from the calpain system. DMF demonstrate semblable mechanism in the cascade of caspases-8, -6, -9, and -3 , and lamin-A compared with 5-Fu, but make a more significant injury on nuclear skeleton and PARP, which may be related to the unique nuclear targeting, the charge, size and shape character of the DMF particles.

Acknowledgments This work was supported by the National Natural Science Foundations of China (81860628, 81860640), Ningxia High School first-class Disciplines (West China first-class Disciplines Basic Medical Sciences at Ningxia Medical University, No. NXYLXK2017B07), and Ningxia key research and development projects (No. 2019BEG03038).

Conflict of Interest The authors declare no conflict of interest.

\section{REFERENCES}

1) Jemal A, Bray F, Center MM, Ferlay J, Ward E, Forman D. Global cancer statistics. CA Cancer J. Clin., 61, 69-90 (2011).

2) Zhang L, Xing Y, Gao Q, Sun X, Zhang D, Cao G. Combination of NRP1-mediated iRGD with 5-fluorouracil suppresses proliferation, migration and invasion of gastric cancer cells. Biomed. Pharmacother., 93, 1136-1143 (2017).

3) Sun Y, Gou GJ, Jin XQ, Zhang M. Intracellular trafficking characteristics for magnetic layered double hydroxide/DNA hybrids to human gastric cancer cell. Applied Mechanics and Materials., 25, 923-928 (2014)

4) Huang J, Gou GJ, Xue B, Yan Q, Sun Y, Dong LE. Preparation and characterization of "dextran-magnetic layered double hydroxide-fluorouracil" targeted liposomes. Int. J. Pharm., 450, 323-330 (2013).

5) Jin XQ, Zhang M, Gou GJ, Ren J. Synthesis and cell imaging of a near-infrared fluorescent magnetic "CdHgTe-dextran-magnetic layered double hydroxide-fluorouracil" composite. J. Pharm. Sci., 105, 1751-1761 (2016)

6) Dong LE, Gou GJ, Jin XQ, Zhang M. Synthesis pretreatment and characterization of a magnetic layered double hydroxides fluorescent probe. Chin. Chem. Lett., 25, 923-928 (2014).

7) Majno G, Joris I. Apoptosis, oncosis, and necrosis. An overview of cell death. Am. J. Pathol., 146, 3-15 (1995).

8) Weerasinghe P, Buja LM. Oncosis: an important non-apoptotic mode of cell death. Exp. Mol. Pathol., 93, 302-308 (2012).

9) Ohno M, Takemura G, Ohno A, Misao J, Hayakawa Y, Minatoguchi S, Fujiwara T, Fujiwara H. "Apoptotic" myocytes in infarct area in rabbit hearts may be oncotic myocytes with DNA fragmentation: analysis by immunogold electron microscopy combined with in situ nick end-labeling. Circulation, 98, 1422-1430 (1998).

10) Buja LM. Myocardial ischemia and reperfusion injury. Cardiovasc. Pathol., 14, 170-175 (2005).

11) Luo D, Ni Q, Ji A, Gu W, Wu J, Jiang C. Dehydroabietic acid derivative QC4 induces gastric cancer cell death via oncosis and apoptosis. Biomed. Res. Int., 2016, 2581061 (2016).

12) Guan R, Chen Y, Zeng L, Rees TW, Jin C, Huang J, Chen ZS, Ji L, Chao H. Oncosis-inducing cyclometalated iridium(iii) complexes. Chem. Sci., 9, 5183-5190 (2018).

13) Pagliara V, Saide A, Mitidieri E, d'Emmanuele di Villa Bianca R, Sorrentino R, Russo G, Russo A. 5-FU targets rpL3 to induce mitochondrial apoptosis via cystathionine-beta-synthase in colon cancer cells lacking p53. Oncotarget, 7, 50333-50348 (2016). 
14) Zhong J, Yang L, Liu N, Zheng J, Lin CY. Knockdown of inhibitor of growth protein 2 inhibits cell invasion and enhances chemosensitivity to 5-FU in human gastric cancer cells. Dig. Dis. Sci., 58, 3189-3197 (2013).

15) Zhu X, Sun Y, Chen D, Li J, Dong X, Wang J, Chen H, Wang Y, Zhang F, Dai J, Pirraco RP, Guo S, Marques AP, Reis RL, Li W. Mastocarcinoma therapy synergistically promoted by lysosome dependent apoptosis specifically evoked by 5-Fu@nanogel system with passive targeting and $\mathrm{pH}$ activatable dual function. J. Control. Release, 254, 107-118 (2017).

16) Qiu G-H, Que W, Yan S, Zheng X, Xie X, Huang C, Yang X, Hooi SC. The pro-survival function of DLEC1 and its protection of cancer cells against 5-FU-induced apoptosis through up-regulation of BCL-XL. Cytotechnology, 71, 23-33 (2019).

17) Chang SH, Phelps PC, Berezesky IK, Ebersberger ML Jr, Trump BF. Studies on the mechanisms and kinetics of apoptosis induced by microinjection of cytochrome $c$ in rat kidney tubule epithelial cells (NRK-52E). Am. J. Pathol., 156, 637-649 (2000).

18) Shiraishi J, Tatsumi T, Keira N, Akashi K, Mano A, Yamanaka S, Matoba S, Asayama J, Yaoi T, Fushiki S, Fliss H, Nakagawa M. Important role of energy-dependent mitochondrial pathways in cultured rat cardiac myocyte apoptosis. Am. J. Physiol. Heart Circ. Physiol., 281, H1637-H1647 (2001).

19) Zhang JY, Wu HY, Xia XK, Liang YJ, Yan YY, She ZG, Lin YC, Fu LW. Anthracenedione derivative 1403P-3 induces apoptosis in $\mathrm{KB}$ and KBv200 cells via reactive oxygen species-independent mitochondrial pathway and death receptor pathway. Cancer Biol. Ther., 6, 1413-1421 (2007).

20) Ma LS, Jiang CY, Cui M, Lu R, Liu SS, Zheng BB, Li L, Li X. Fluopsin $\mathrm{C}$ induces oncosis of human breast adenocarcinoma cells. Acta Pharmacol. Sin., 34, 1093-1100 (2013).

21) Wang L, Hu T, Shen J, Zhang L, Li LF, Chan RL, Li MX, Wu WK, Cho $\mathrm{CH}$. Miltirone induced mitochondrial dysfunction and ROSdependent apoptosis in colon cancer cells. Life Sci., 151, 224-234 (2016).

22) $\overline{\mathrm{Du} \mathrm{JH}}$, Zhang HD, Ma ZJ, Ji KM. Artesunate induces oncosis-like cell death in vitro and has antitumor activity against pancreatic cancer xenografts in vivo. Cancer Chemother. Pharmacol., 65, 895-902 (2010).

23) Sayeed A, Meng Z, Luciani G, Chen LC, Bennington JL, Dairkee $\mathrm{SH}$. Negative regulation of UCP2 by TGFbeta signaling characterizes low and intermediate-grade primary breast cancer. Cell Death Dis., 1, 1-12 (2010).

24) Horimoto M, Resnick MB, Konkin TA, Routhier J, Wands JR, Baffy G. Expression of uncoupling protein-2 in human colon cancer. Clin. Cancer Res., 10, 6203-6207 (2004).

25) Zou ZZ, Nie PP, Li YW, Hou BX, Rui-Li, Shi XP, Ma ZK, Han BW, Luo XY. Synergistic induction of apoptosis by salinomycin and gefitinib through lysosomal and mitochondrial dependent pathway overcomes gefitinib resistance in colorectal cancer. Oncotarget, 8 , 22414-22432 (2017).

26) Selimovic D, Hassan M, Haikel Y, Hengge UR. Taxol-induced mitochondrial stress in melanoma cells is mediated by activation of c-Jun N-terminal kinase (JNK) and p38 pathways via uncoupling protein 2. Cell. Signal., 20, 311-322 (2008).

27) Robbins D, Zhao Y. New aspects of mitochondrial uncoupling proteins (UCPs) and their roles in tumorigenesis. Int. J. Mol. Sci., 12, 5285-5293 (2011).

28) Jin L, Qu HE, Huang XC, Pan YM, Liang D, Chen ZF, Wang HS, Zhang Y. Synthesis and biological evaluation of novel dehydroabietic acid derivatives conjugated with Acyl-thiourea peptide moiety as antitumor agents. Int. J. Mol. Sci., 16, 14571-14593 (2015).
29) Saikumar P, Dong Z, Patel Y, Hall K, Hopfer U, Weinberg JM, Venkatachalam MA. Role of hypoxia-induced Bax translocation and cytochrome $c$ release in reoxygenation injury. Oncogene, 17, 3401-3415 (1998)

30) Zhang C, Xu Y, Gu J, Schlossman SF. A cell surface receptor defined by a mAb mediates a unique type of cell death similar to oncosis. Proc. Natl. Acad. Sci. U.S.A., 95, 6290-6295 (1998).

31) Cooley-Andrade O, Goh WX, Connor DE, Ma DD, Parsi K. Detergent sclerosants stimulate leukocyte apoptosis and oncosis. Eur. J. Vasc. Endovasc. Surg., 51, 846-856 (2016).

32) Ohno M, Takemura G, Ohno A, Misao J, Hayakawa Y, Minatoguchi S, Fujiwara T, Fujiwara H. "Apoptotic" myocytes in infarct area in rabbit hearts may be oncotic myocytes with DNA fragmentation: analysis by immunogold electron microscopy combined with in situ nick end-labeling. Circulation, 98, 1422-1430 (1998).

33) Katona C, Timar F, Olah J, Bocsi J, Budai B, Otvos L, Kralovanszky J. Potentiation of 5-fluorouracil efficacy. Molecular mechanisms playing a role in the cytotoxic action of 5-fluorouracil and 5-ethyl-2'-deoxyuridine (EUdR) combination. Magy. Onkol., 48, 243-251 (2004)

34) Tong Q, Wu L, Jiang T, Ou Z, Zhang Y, Zhu D. Inhibition of endoplasmic reticulum stress-activated IRE1alpha-TRAF2-caspase-12 apoptotic pathway is involved in the neuroprotective effects of telmisartan in the rotenone rat model of Parkinson's disease. Eur. J. Pharmacol., 776, 106-115 (2016).

35) Nakagawa T, Yuan J. Cross-talk between two cysteine protease families. Activation of caspase-12 by calpain in apoptosis. J. Cell Biol., 150, 887-894 (2000).

36) Song J, Zhang Q, Wang S, Yang F, Chen Z, Dong Q, Ji Q, Yuan X, Ren D. Cleavage of caspase-12 at Asp94, mediated by endoplasmic reticulum stress (ERS), contributes to stretch-induced apoptosis of myoblasts. J. Cell. Physiol., 233, 9473-9487 (2018).

37) Nakagawa T, Zhu H, Morishima N, Li E, Xu J, Yankner BA, Yuan J. Caspase-12 mediates endoplasmic-reticulum-specific apoptosis and cytotoxicity by amyloid-beta. Nature, 403, 98-103 (2000).

38) Yao H, Tang X, Shao X, Feng L, Wu N, Yao K. Parthenolide protects human lens epithelial cells from oxidative stress-induced apoptosis via inhibition of activation of caspase-3 and caspase-9. Cell Res., 17, 565-571 (2007).

39) Ryu D-S, Lee H-J, Kwon J-H, Lee D-S. Anti-cancer effect of ethylacetate fraction from Orostachys japonicus on HT-29 human colon cancer cells by induction of apoptosis through caspase-dependent signaling pathway. Asian Pacific Journal of Tropical Medicine, 11, $330-335$ (2018).

40) Grunert M, Gottschalk K, Kapahnke J, Gundisch S, Kieser A, Jeremias I. The adaptor protein FADD and the initiator caspase- 8 mediate activation of NF-kappaB by TRAIL. Cell Death Dis., 3, $1-13$ (2012).

41) Arnault E, Doussau M, Pesty A, Lefevre B, Courtot AM. Review: lamin $\mathrm{A} / \mathrm{C}$, caspase-6, and chromatin configuration during meiosis resumption in the mouse oocyte. Reprod. Sci., 17, 102-115 (2010).

42) Shahzidi S, Brech A, Sioud M, Li X, Suo Z, Nesland JM, Peng Q. Lamin A/C cleavage by caspase-6 activation is crucial for apoptotic induction by photodynamic therapy with hexaminolevulinate in human B-cell lymphoma cells. Cancer Lett., 339, 25-32 (2013).

43) Cowling V, Downward J. Caspase-6 is the direct activator of caspase- 8 in the cytochrome $c$-induced apoptosis pathway: absolute requirement for removal of caspase-6 prodom. Cell Death Differ., 9 , 1046-1056 (2002).

44) Slee EA, Adrain C, Martin SJ. Executioner caspase-3, -6, and -7 perform distinct, non-redundant roles during the demolition phase of apoptosis. J. Biol. Chem., 276, 7320-7326 (2001). 